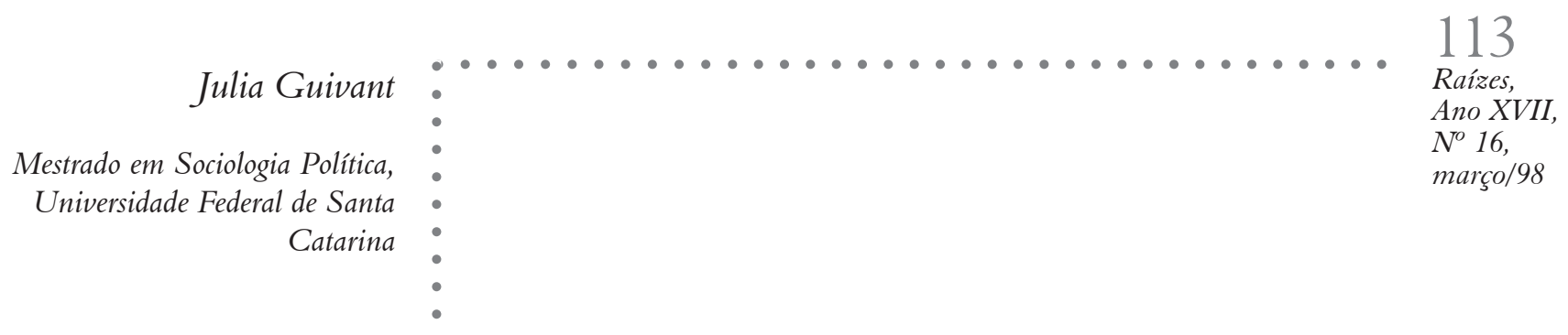

\title{
Suinocultura e Poluicão no Oeste de Santa Catarina: Os Desafios de Implementar uma Política Ambiental
}

\section{I- Introdução}

Ainda no Brasil, a formulação de políticas dirigidas ao controle ambiental da produção agrícola é pouco significativa. Algumas iniciativas estão sendo implementadas a nível regional, mas não chegam a eliminar o contraste com as políticas dirigidas ao controle da poluição industrial.

Uma das razões que explicam esta diferença é que os controles ambientais convencionalmente têm sido formulados, em grande parte, através de standards específicos que possibilitam sua regulamentação e implementação em focos concentrados de poluição. Este tipo de controle é limitado na sua aplicação para a agricultura, dado que as práticas agrícolas caracterizam-se principalmente por serem fontes difusas de efluentes.
Além desse desafio, há outros não menos importantes para o controle dos impactos ambientais das práticas agrícolas, como os conflitos políticos e sociais devidos ao grande número de pequenas propriedades rurais, fatores que introduzem limitações para a transferência de custos adicionais para o setor; importância estratégica da agricultura, que gera relutância para impor custos que possam ameaçar sua posição na balança de pagamentos; inflexibilidade dos fatores produtivos, sendo os solos um recurso central; e, também, problemas de implementação administrativa e de monitoramento (Gasbergen, 1992; Bruckmeier e TeheraniKrönner, 1992; Seymour e Cox, 1992; Jokinen, 1995; Lowe, 1992). A essas dificuldades básicas para controlar o que acontece no meio ambiente rural, somam-se no Brasil, assim como em outros países do Sul, as carências de recursos técnicos e de pessoal nas agências ou órgãos governamentais com atribuições para tal controle.

Uma iniciativa recente, ainda em fase de implementação, para enfrentar um dos problemas de poluição agrícola mais sérios que afetam a região sul do Brasil é a proposta pelo Programa de Expansão da Suinocultura e Tratamento de seus Dejetos (a seguir, referido como "Programa"). Com financiamento do Banco de Desenvolvimento Econômico e Social (BNDES) e coordenação do Governo estadual, o Programa visa no prazo de 5 anos, a partir de 1994, o controle da poluição ocasionado pela intensiva produção de suínos em Santa Catarina, particularmente no oeste, onde estima-se que entre 80 e $90 \%$ dos rios estão contaminados por dejetos. O projeto é considerado pelo BNDES como modelo para aplicar em outros estados (Mato Grosso do Sul, Rio Grande do

- * Agradeço ao CNPq o financiamento da pesquisa e a Cláudio Miranda sua valiosa colaboração no - trabalho de campo e na discussão dos dados. 
Sul e Paraná), e representa um novo fluxo de créditos - US\$100 milhões -, que pode afetar o perfil da suinocultura na região.

Os financiamentos oferecidos para os agricultores destinam-se a implantar esterqueiras e bioesterqueiras, procurando-se um uso mais adequado dos dejetos como fertilizantes nas lavouras de milho, por sua vez um dos componentes básicos da alimentação dos suínos. Junto a este objetivo ambiental, o Programa visa também estimular a modernização da suinocultura, prevendo investimentos para o aumento das dimensões das instalações para criação de leitões, aquisição de matrizes, etc.

Diversos atores estão sendo mobilizados em torno da formulação e implementação das propostas do Programa: agricultores, técnicos, representantes das agroindústrias e cooperativas, políticos, líderes sindicais, pesquisadores e funcionários dos bancos e de órgãos governamentais. Mas nem todos têm os mesmos pontos de vista a respeito da natureza, extensão e conseqüências do que é poluição, nem sobre as estratégi- as para enfrentá-la.

Neste artigo, analisa-se como as diferentes percepções da questão ambiental afetam a implementação do Programa, discutindo-se como o objetivo ambiental é comprometido pelo destaque dado ao outro objetivo do Programa, o da modernização da suinocultura $^{1}$.

\section{II - A Emergência do Proble- ma}

A suinocultura no Brasil tem sido uma atividade fundamentalmente desenvolvida em pequenas propriedades rurais, com destacado papel no estado de Santa Catarina, que conta com $80 \mathrm{mil}$ suinocultores, $80 \%$ dos quais situam-se na região oeste, com uma média de 16 hectares por criador. Em torno de 28 mil produtores são integrados as grandes agroindústrias (privadas e cooperativas) localizadas nessas áreas, como a Sadia, Perdigão, Ceval, Chapecó, Coopercentral e Eliane, sendo o restante produtores independentes. Pode-se dimensionar a importância deste setor, incluindo produção, industrialização e comercialização, considerando que gera mais de $150 \mathrm{mil}$ empregos e é uma das mais importantes fontes de impostos do Estado.

A produção catarinense de suínos é a maior do país, com 29,6\% do total nacional, para um rebanho de 3,35 milhões de cabeças suínas, o que representa $11,2 \%$ do rebanho nacional e um desfrute de $140 \%$ contra a média nacional de $51,3 \%$. As agroindústrias do oeste de SC caracterizam-se pela sua forte orientação para o mercado internacional. A importância desta orientação pode ser exemplificada com o caso da Sadia, a maior exportadora de carnes da América Latina, com uma carteira de 200 clientes em 40 países. Tem subsidiárias em Tóquio, Milão e Buenos Aires, além de contar no território nacional com 150 mil pontos de venda em 1600 municípios. Das 5 áreas nas quais atua, lidera em aves, carnes industrializadas e suínos. Conta com 5 mil integrados de aves e 12.700 de suínos. Com 32.400 funcionários, opera 24 plantas indústrias e possui 18 filiais regionais de comercialização. Em ram realizadas entrevistas abertas com representantes de agroindústrias e cooperativas, um líder sindical, o Secretário de Agricultura e o Secretário de Saúde do município de Concôrdia, o coordenador do Programa, também presidente da Associação Catarinense de Criadores de Suínos - (ACCS), pesquisadores do Centro Nacional de Pesquisa em Suínos e Aves (EMBRAPA/CNPSA) e - do Centro de Pesquisas da Pequena Propriedade (CPPP), técnicos da Empresa de Pesquisa e Ex- tensão de Santa Catarina (EPAGRI), encarregados nos bancos de repassar o financiamento, res- ponsável na Fundação de Amparo e Tecnologia ao Meio Ambiente de Santa Catarina (FATMA) de - dar os laudos técnicos e a responsável do Programa de Despoluição dos Rios do Vale do Itajaí, repre- sentantes da Associação dos Pequenos Produtores do Oeste Catarinense (APACO) mais 8 entrevis- tas piloto com agricultores em Concórdia e Chapecó e 45 questionários aplicados em São Miguel - do Oeste. Também foram acompanhadas reuniões de avaliação do Programa. 
1995, exportou mais de US\$ meio bilhão, o que mostra sua presença consolidada nos mercados internacionais.

O desenvolvimento da suinocultura passou a ser mais marcante a partir da década de 70 . Em pouco tempo, particularmente a região do oeste de Santa Catarina se transformou numa grande produtora não só de suínos, mas também de frangos, perus e derivados de soja, através da integração entre lavoura, criação e frigoríficos. Nos últimos 10 anos, começou gradativamente um processo de transformação na suinocultura, no qual as agroindústrias passaram a pressionar os integrados para um maior aumento da produtividade, tendose como meta passar de uma média anual de 16 para 23 suínos terminados por matriz e de 20 terminados/porca por ano. Esta meta tem impactos regionais significativos porque leva à redução do número de integrados - excluindo os pequenos produtores que têm em torno de 5 criadeiras com aumento de área e do plantel médio por propriedade.

Além do sistema tradicional de ciclo completo, está emergindo desde o início dos anos 90 o padrão de criação especializado na produção de leitões e na terminação, visando garantir o au- mento da produtividade, a melhoria na qualidade do produto e a manutenção de um fluxo mais regular na obtenção de matéria prima $^{2}$. Através da especialização, as agroindústrias passam a ter um maior controle sobre o processo produtivo, fundamentalmente com o fornecimento de material genético, alimentação e acompanhamento das práticas de manejo, que garantem um cronograma mais rigoroso da produção. Esse processo de concentração e especialização segue a tendência internacional que se tem configurado desde os anos 80, e que apresenta as vantagens da produção em escala.

O problema que isto ocasiona é que a quantidade de esterco produzido geralmente não tem onde ser utilizado, porque a área arável tem diminuído, e o preço bem como o trabalho envolvido com fertilizantes químicos fazem com que estes sejam preferidos. A poluição passou a ter um caráter mais grave devido à adoção de sistemas de confinamento nos anos 70, sem que mudasse a localização das instalações perto dos cursos de água. Com esta intensificação, os dejetos deixaram de receber um tratamento adequado, com apenas de 10 a $15 \%$ dos suinocultores dispondo, atualmente, de sistemas de tratamento ou aproveitamento.
Ainda que na região não tenham sido realizadas pesquisas sistemáticas sobre o impacto poluidor dos fatores acima mencionados nem sobre as conseqüências para a saúde da população e o equilibro ambiental, já desde meados dos anos 80 começaram a ser acumuladas evidências técnicas parciais sobre a dimensão da contaminação dos rios no oeste do estado de Santa Catarina, apontando níveis muito superiores aos parâmetros recomendáveis. Paralelamente à divulgação dos dados, um clima de alarma foi emergindo em algumas comunidades, mas mínimas medidas foram tomadas pelos órgãos de controle ambiental do estado. Isto contrasta com os procedimentos para o controle dos efluentes das agroindústrias lançados nos rios. Entre 1987 e 1989, o órgão governamental de controle ambiental do estado, FATMA, implantou, em Santa Catarina, quatro programas de despoluição das bacias hidrográficas, que previam a instalação de equipamentos de tratamento de efluentes líquidos nas empresas responsáveis pelo despejo dos dejetos industriais nos rios do Estado. Este controle implementado pela FATMA, seguindo a legislação ambiental do Estado no referente à responsabilidade das indústrias no tratamento de seus efluentes, teve um resultado positivo e com

- 2 O produtor de ciclo completo é o que se dedica desde a produção de leitões até a sua terminação,

- com aproximadamente $100 \mathrm{~kg}$, ou 150 dias. O terminador é o produtor que se especializa apenas na

- engorda dos suínos (fase de crescimento e terminação) e produtor de leitões é quem possui matrizes

- e reprodutores visando apenas produzir leitões, quando os mesmos atingem aproximadamente 24

kg, ou seja em torno de 70 dias, quando são transferidos para outros produtores. 
alta repercussão na opinião pública. Entretanto, o conjunto dessas pressões efetivas da FATMA não se estendeu à poluição que se origina nas propriedades dos suinocultores integrados. Para a FATMA, o problema da poluição finaliza na relação direta indústria-meio ambiente, ainda que a legislação ambiental de SC inclua diversas exigências aplicáveis à suinocultura. Dessa maneira, os assuntos relativos à estocagem e distribuição dos dejetos animais acabam atrelados ao voluntarismo dos produtores, que não encontram interferências para o que acontece dentro de suas propriedades.

As ações de comunidades e prefeituras, somadas à acumulação de evidências científicas sobre os níveis de poluição dos rios, contribuíram na construção de um clima propício para tomar medidas que focalizem no tratamento dos dejetos nas propriedades rurais. Outros atores passaram a intervir assumindo tal questão, atentos à receptividade que a questão ambiental passou a receber no BNDES, com uma linha de crédito especial com juros mais baixos. Lideranças políticas regionais e pesquisadores do Centro Nacional de Pesquisas em Suinoculturas da EMBRAPA, que é localizado na região oeste, levantaram a necessidade de se tomar medidas urgentes para o controle da poluição. A diretoria do banco acabou integrando estratégias visando o problema ambiental com outras que estimulam o aumento da produção e da produtividade da suinocultura na região. As agroindústrias e as cooperativas apoiaram esta combinação, com o argumento de que se fosse exclusivamente o financiamento para a questão ambiental, os produtores não teriam interesse em assumir a dívida.

\section{III - A Implementação do Programa}

Desde seu início, o Programa foi estimulando a convergência de diversos atores em torno de seus objetivos e, dessa maneira, reunindo os fatores que podem considerar-se centrais para converter a questão ambiental num problema regional relevante. Entre estes fatores podem mencionar-se os seguintes: 1) estimulou a atenção da mídia, destacandose o peso do argumento sobre o retorno econômico do controle ambiental, numa estimativa de que Santa Catarina poderá colocar-se em condições de competitividade para enfrentar a concorrência do Mercosul e outros mercados internacionais, com uma economia estimada entre US $\$ 40$ e US\$ 60 milhões anuais no uso de adubos químicos; 2) envolveu uma parte do governo; 3) demandou decisão governamental; 4) não é considerado pelo público como um evento único; e 5) se relaciona com o interesse pessoal de um número significativo de cidadãos (Hanningan, 1995).

Até o momento, predominam os financiamentos que objetivam a expansão e implantação de instalações e matrizes, contra a reduzida demanda para atividades relacionadas exclusivamente com a conservação do meio ambiente. Observa-se também uma baixa demanda de recursos para investir em equipamentos. Em relação à finalidade da demanda por recursos, ainda que só $2,5 \%$ dos contratos sejam destinados exclusivamente à conservação do meio ambiente, isto não significa que o restante dos financiamentos não incluem este aspecto. Todos os projetos devem dedicar uma percentagem dos recursos à construção de esterqueiras ou bioesterqueiras, ainda que não seja estipulado quanto do total.

O Programa, ao centrar a sua proposta ambiental nesta alternativa técnica, pressupõe um conjunto ideal de operações, inspeções, manejo ou manutenção de práticas consideradas seguras ou adequadas, distante das complexidades, contradições e incoerências do mundo real. O mundo ideal do Programa é povoado por suinocultores interessados em controlar a poluição e se modernizar, que vão construir esterqueiras ou bioesterqueiras dentro das recomendações técnicas, distribuir o fertilizante no momento e nas condições mais adequadas, manter as instalações em correto estado e finalmente desfrutar rios limpos, com um controle adequado da poluição. Também neste quadro ideal, entram técnicos de agroindústrias preocupados com o problema ambiental e capacitados para avaliar as especifi- 
cidades das propriedades em termos de localização e dimensão das bioesterqueiras.

O "actor-world" dos agricultores é muito mais complexo que esse ideal. Considerando-se que os suinocultores são atores chaves no controle da poluição, este vai depender de como aqueles percebem os riscos decorrentes dos dejetos, definem as responsabilidades da poluição, interessam-se em assumir o financiamento, avaliam o Programa e as instituições que dele participam, e realizam as diversas tarefas necessárias para diminuir o conteúdo líquido dos dejetos e manter em bom estado as bioesterqueiras uma vez construídas. Estes diversos aspectos são desatendidos dentro da proposta, que enfatiza o recurso à tecnologia como condição suficiente para atingir os objetivos.

Que significa a poluição para os suinocultores?. Eventos de poluição de maiores magnitudes e conseqüências diretamente detectáveis, como mortandade de peixes, ou alta proliferação de borrachudos, moscas e pernilongos, tendem a ser reconhecidos pelos suinocultores como parte de um "problema", algo que deveria ser enfrentado e transformado. Também a resistência do gado a beber nos cursos de água e o cheiro às vezes considerado insuportável são apontados como sintomas preocupantes. Para a grande maioria dos produtores, a poluição permanece como um pano de fundo distante das preo- cupações e tarefas cotidianas. Nas entrevistas, são pouco freqüentes as referências ou temores sobre o que pode acontecer à saúde humana, e nem sempre a poluição por dejetos é considerada o maior problema ambiental da região. A percepção dos riscos ambientais não pode ser isolada de outras percepções, valores e objetivos que permeiam as estratégias dos suinocultores. Por que fazer um investimento em controle ambiental, quando as prioridades de investimento podem ser outras, face às necessidades consideradas mais prementes?

Isto chama a atenção sobre um fator crucial para o controle de poluição: o quadro de falta de perspectivas econômicas da suinocultura. Dadas as suas constantes crises, com baixo preço do quilo/porco e alto preço do milho, há poucas condições e motivação por parte dos produtores para assumir dívidas com juros ou planejar investimentos no controle de dejetos. As agroindústrias não dão aos suinocultores, frente aos bancos, o aval necessário para tomar o financiamento. Esta negativa desestimula muitos produtores de assumirem o crédito, porque para isto devem hipotecar suas propriedades. As cooperativas, pelo contrário, têm uma política diferente, assumindo tal aval. Os seus integrados pagam em $\mathrm{kg}$ de porco, o que acaba estimulando maior número de cooperativados a entrar no Programa.
Também há uma significativa desconexão entre suinocultores e o órgão que assumiu a coordenação técnica do Programa, a Associado Catarinense de Criadores de Suínos, ACCS, devido à falta de representatividade legítima desta, que acaba afetando a legitimidade das próprias medidas de controle ambiental frente aos agricultores.

As agroindústrias e cooperativas mantêm, nas propriedades de seus integrados, a mesma política de descomprometimento em relação à questão ambiental que assumem em relação a outros problemas que afetam àqueles, $\mathrm{e}$ priorizam a modernização da produção. Até o presente, estas empresas não assumiram responsabilidades sobre o treinamento dos agricultores na manutenção das esterqueiras e bioesterqueiras, nem sobre como se realiza a sua construção. Os técnicos das agroindústrias, que visitam as propriedades pelo menos uma vez por mês, para dar assistência aos suinocultores, são figuras chaves na implementação do Programa, mas com pouco tempo para dedicar a cada suinocultor. Por isso, eles encontram limites objetivos para incorporar mais outra atividade a sua lista de assuntos. O trabalho que eles devem realizar para o Programa passa a ser mais uma tarefa demorada e cansativa, muitas vezes assumida contra sua vontade.

O centro nacional de pesquisas em suinocultura, EMBRAPA/ CNPAS, ainda que desde 1992 
coloque a questão dos dejetos como uma de suas prioridades, até o presente só tem três pesquisadores trabalhando nisto. Esses pesquisadores vêem com ceticismo a possibilidade de atingir seus objetivos através da tecnologia proposta, mas suas pesquisas ainda se encontram em andamento, sem condições de serem difundidas.

Estas diferenças de perspectivas sobre como enfrentar o problema ambiental somadas à falta de um significativo envolvimento dos suinocultores, acabam afetando a implementação da proposta ambiental do Programa, que está sendo executado num esquema de cima para baixo, com uma proposta corporativista.

\section{IV - Conflitos entre Controle Ambiental e Expansão da Suinocultura}

Os financiamentos procuram estimular também a "modernização da produção”, o que significa expansão e, mais ainda, seguindo as tendências dos últimos anos, especialização. Mas quem polui mais? São os grandes e médios produtores, que concentram a produção da fase de crescimento e terminação, representando quase $70 \%$ da produção de dejetos. Para esses sistemas de criação, que podem incluir suinocultores com mais de 50 matrizes em ciclo completo, ou mais de 400 cabeças em unidades de terminação, ou ainda 150 matrizes em criação de leitões, as alternativas de armazenamento propostas no Programa são consideradas inadequadas pelos pesquisadores da EMBRAPA. A construção de lagoas de tratamento seria o mais apropriado. Essas lagoas podem tratar os dejetos de forma a que o material líquido possa voltar aos rios sem ameaça de poluição. Essa estratégia está dificultada por falta de área disponível ou por falta da declividade necessária (acima de 40 matrizes precisase de área plana, algo raro na região), além de seu alto custo de construção. Ainda supondo que essas lagoas de tratamento fossem construídas, surge o problema de, assim, aumentar os riscos de acidentes de poluição de maiores proporções.

O Programa expõe os limites de tratar o problema da poluição desvinculado das características da produção. Por um lado, cria a impressão de que, controlando os dejetos com novo tipo de depósitos, se elimina seu impacto ambiental. Por outro lado, distanciamse os termos do debate regional de um questionamento mais aprofundado sobre a redução da quantidade de animais por ha. e sobre a importância de uma qualificação dos produtores para um manejo mais equilibrado dos recursos naturais, assim como sobre o nível de responsabilidade das agroindústrias.

Qualquer alternativa para superar os limites que apresentam as propostas do Programa deve surgir de um debate mais amplo que integre as diferentes perspectivas dos atores envolvidos na suinocultura, incorporando também os que têm sido excluídos do Programa. Isto implicará entrar num processo complexo de negociações sobre o que se entende por poluição e qual é a sua relevância em termos regionais.

As dificuldades de atingir um consenso sobre diagnósticos e propostas emergem ao se considerar as posições de duas entidades da região que assumem a sustentabilidade agrícola como objetivo central para o desenvolvimento e que não participam do Programa. Estas são uma ONG, a Associação dos Pequenos Agricultores do Oeste Catarinense (APACO), e o Centro de Pesquisa da Pequena Produção (CPPP), integrado por pesquisadores e técnicos do órgão governamental do estado de Santa Catarina para a pesquisa e extensão rural, EPAGRI. A APACO, que começou suas atividades em 1989, como parte da confluência entre o movimento sindical rural e um setor da Igreja Católica, na procura de estratégias alternativas de sobrevivência da pequena produção familiar, destaca-se pelo estímulo associativo que trata de difundir entre produtores para que realizem em conjunto a produção e comercialização. Embora os líderes da APACO apresentem uma perspectiva crítica ao modelo produtivo dominante na região, assumindo a sustentabilidade como um objetivo central de seu trabalho, a questão ambiental, e mais especificamente a poluição 
por dejetos suínos, não aparece incluída concretamente nas suas propostas, nem tem tido envolvimento com o Programa. Este último aspecto deve-se a uma crítica política à liderança do Programa, que se avalia como ligada aos interesses da agroindústria e não dos suinocultores. Esta caracterização do Programa leva também outros atores a se manterem distantes, como é o caso do Sindicato Rural, que tampouco participa da rede.

O Centro de Pesquisa da Pequena Produção (CPPP), de Chapecó, elaborou este ano um documento sobre as perspectivas de uma estratégia regional de desenvolvimento sustentável, que organiza competentemente um conjunto de propostas concretas em diversas áreas (Testa et al., 1996). Segundo os autores, o problema da poluição pelos dejetos suínos é uma questão menor frente a outro problema ambiental mais sério que afeta a região, a erosão dos solos.

Sem entrar na discussão sobre qual é o maior problema ambiental, deve considerar-se como os autores do documento propõem enfrentar a poluição por dejetos. Para eles, a solução é simples, pois localizam a origem do problema num número restrito de suinocultores, os maiores, em torno de 12 mil que, segundo os autores do documento, podem ser facilmente orientados, controlados e fiscalizados, além de contarem com recursos para corrigir a situação. Mas a solução proposta permanece no plano técnico, aproximando-se em alguma maneira da formulada pelo Programa. Desconsidera-se que esta solução deve ser mediada por diferentes circunstâncias sociais, econômicas e culturais em nível das propriedades rurais, e que não necessariamente os agricultores estão dispostos ou em condições de implementar o que emana de outras arenas. Ainda que dentro de uma proposta muito mais ampla e fundamentada que a do Programa, este documento também apresenta certos pressupostos de uma "sociologia ingênua" sobre como os agricultores reagiriam frente às pressões e estímulos externos (Wynne, 1989; Clark e Lowe, 1992). Estes pressupostos estendem-se a como é caracterizado o envolvimento das agroindústrias e cooperativas no controle ambiental. Este, longe de ser simples, implica complexas negociações para que estas empresas assumam responsabilidades pelo que acontece nas propriedades de seus integrados.

E aqui pode passar a ter peso a forte orientação destas agroindústrias para o mercado internacional. Os efeitos disso podem ir em duas direções que, em princípio, aparecem como contraditórias: uma, estimulando a concentração e especialização em vista à competitividade da produção; outra, assumindo práticas que não agridam o meio ambiente, o que pode passar a ser importante em termos da imagem geral das empresas e da necessidade de sintonizar-se com as exigências am- bientais dos importadores e dos bancos internacionais. Um maior peso da segunda direção levará a uma redefinição da competitividade, além de um significado econômico restrito, podendo-se incluir aqui condições de sustentabilidade para a produção familiar diversificada, ainda que dentro de um processo seletivo.

A formulação de medidas que atinjam as causas da poluição em combinação com políticas agrícolas que estimulem a diversificação produtiva e garantam a sobrevivência da produção familiar diversificada, visando um desenvolvimento sustentável e envolvendo os diversos atores chaves na região, não é um processo simples. Entra-se aqui numa trajetória de conflitos, negociações, gerações de alianças, mobilizações e transações de recursos, influências e significados, envolvendo atores, tecnologias e processos ambientais, interagindo em diferentes arenas.

\section{$V-$ Conclusões}

As diversas posições em relação ao Programa expõem dificuldades para que este consiga não só obter legitimidade mas também gerar consenso em torno da questão ambiental. Ainda há atores que assumem como legítima uma proposta de sustentabilidade e apresentam mais uma divergência em torno da importância da questão da poluição pelos dejetos. Dessa maneira, o primeiro 
intento de maior escala de enfrentar este problema ambiental encontra dissonâncias, tanto com os atores mobilizados como com os atores que potencialmente poderiam ser aliados conjunturais.

A política ambiental aqui discutida não é simplesmente uma primeira etapa de um processo linear de controle a mais longo prazo. Este Programa, ao assumir uma visão produtivista da suinocultura e uma visão tecnocrática da poluição, que não se articulam, pode estimular resultados contraditórios com suas metas ambientais explícitas, assim como incidir no agravamento dos problemas já enfrentados pelos suinocultores na manutenção de um sistema produtivo diversificado. Entretanto, é importante reconhecer que o Programa pode estar gerando um patamar de debates inédito na região, assim como abrindo espaços de negociação sobre questões ambientais das lideranças locais com as autoridades do governo estadual e os representantes do BNDES. Além disto, há o envolvimento, ainda que limitado, das agroindústrias, assumindo certa necessidade de medidas ambientais, o que vai ao encontro de seus interesses no contexto do mercado globalizado.

\section{VI - Bibliografia Citada}

BALDOCK, D. e G. BENNETT (1991) Introduction, In D. Baldock e G. Bennett (eds.) Agri- culture and the Polluter Pays Principle. A study of six EC countries. London: Institute for Environmental Policy.

BRUCKMEIER, K. e P. TEHERANI-KRÖNNER (1992) Farmers and environmental regulation. Experiences in the Federal Republic of Germany. In Sociologia Ruralis, Vol. XXXII, $\mathrm{n}^{\circ} .1$ : 66-81.

CLARK, J. e P. LOWE (1992) Cleaning up agriculture: ennvironment, technology and social science. In Sociologia Ruralis, Vol. XXXII, $n^{\circ} .1: 11-29$.

GLASBERGEN, P. (1992) Agro-environmental policy: trapped in an iron law? A comparative analysis of agricultural pollution control in the Netherlands, the United Kingdom and France. In Sociologia Ruralis, Vol .XXXII, nº.1: 30-48.

HANNINGAN, J. (1995) Environmental sociology. A social constructionist perspective. London: Routledge JOKINEN, P.(1995) The development of agricultural pollution control in Finland. In Sociologia Ruralis, Vol. XXXV, N. 2:206-227.

LOWE, P. (1992). Industrial agriculture and environmental regulation: a new agenda for rural sociology. In Sociologia Ruralis, Vol .XXXII, nº.1: 4-10.

SEYMOUR, S. e G. COX (1992) Nitrates in water: the politics of pollution regulation. In A. Gilg (ed.), Restructuring the countryside: environmental policy in practice. London: Ashgate $\mathrm{Pu}$ blishing Ltd.

TESTA, V., R. NADAL, L. MIOR, I. BALDISSERA e N. CORTI-
NA (1996) O desenvolvimento sustentável do Oeste Catarinense (Proposta para Discussão). Florianópolis: Epagri.

WYNNE, B. (1989) Frameworks of rationality in risk management: towards the testing of naïve sociology. In J. Brown (ed.), Environmental threats: perception, analysis and management. London: Bellhaven Press 